\title{
Organization Culture - Oriented Training Design
}

\author{
Darwis Agustriyana ${ }^{1}$, Gusni $^{1}$, Didi Tarmidi ${ }^{1} \&$ Dinda Kayani Putri Bestari ${ }^{1}$ \\ ${ }^{1}$ Department of Management, Widyatama University, Bandung, Indonesia \\ Correspondence: Darwis Agustriyana, Department of Management, Widyatama University, Bandung, Indonesia.
}

Received: April 30, 2019

Accepted: May 30, 2019

Online Published: June 10, 2019

doi:10.5430/ijfr.v10n5p82

URL: https://doi.org/10.5430/ijfr.v10n5p82

\begin{abstract}
This study aims to analyze the implementation of an organizational culture that is applied and the expected Bandung Polytechnic LP3I in four years to come, through OCAI profile mapping method to obtain the organizational culture profile Bandung Polytechnic LP3I current of the order of the highest to the lowest impact. Mixed data retrieval technique that is parallel both quantitative and qualitative. Where quantitative and qualitative data collected in the same time and analyzed to complement each other. The results of the training needs analysis based on gap indicates that the required training, organizational culture oriented to improving the market and adhocracy organizational culture.
\end{abstract}

Keywords: training design, organizational culture, OCAI

\section{Introduction}

Culture binds the employees to behave in accordance with the existing culture. Related to that understanding, a set of norms has become a culture in the organization; employees will act and behave in accordance culture without forced. If the culture directing employees to have a good performance, it is certain that all employees will do their job properly because they consider it as a cultural norm. Furthermore, organizational culture goes in line with organizational goals, if the culture implemented well, it is expected to improve the performance of employees that have an impact on the achievement of organizational goals. The types of organizational culture by Cameron \& Quinn (2006) in terms of flexibility and stability as well as internal and external, consisting of clan, Hierarchy, Sandy,(2018) Adhocracy and market. Naturally, one of which became a corporate organizational culture.

Organizational culture also requires employees to systematically improving its performance for the company. Robbins (2006) said that to achieve success an organization need to improve organizational performance factors by creating and developing an organizational culture. Weakening of organizational culture Symptoms in a company can be seen from the overall organizational performance, the low level company's employees turnover (entry and exit), and high and low levels of employee absenteeism. Gamba (2017) Therefore, organizational culture cannot be separated from the behavior of its employees; it indicates a strong relationship between the organization and the Human Resources (HR).

Education institutions of Bandung Polytechnic LP3I is one of the educational institutions concerned about the organizational culture, it is seen from several things including all employees, managerial and faculty are required to wear identity cards and the company's organizational culture that are behind it. the company also has provided several training that support the implementation of organizational culture, although in its activities, Bandung Polytechnic LP3I experiencing problems that often arise from internal, where employees sometimes cannot understand the values contained in the company about how they should behave accordance with the existing organizational culture and also less discipline in keeping the body in work and training agenda that has been set due to the emergent institution interests associated with the values that exist within the company. Therefore the purpose of the organizational culture is less effective in its implementation and employees tend to behave as he pleases, causing a decrease in employee performance.

Weakness indications of the organizational culture implementation in Bandung Polytechnic LP3I can be seen from the declining performance of employees, there are still pretty much going on the fact that less in line with expectations that the low employee work ethic. This can be proved also by the number of employees who are not on time at the office, delaying the office tasks, out of the office during office hours and the employee absenteeism high 
intensity (Rakab 2018; Shi, et. al., 2018). This shows a decrease in employee performance characterized by decreasing employee productivity.

Human resource quality development training has been carried out but did not show an optimal effect to the application of organizational culture, it is a form of failure of the human resource quality development program. Therefore the need for specific studies aimed at identifying the weaknesses of human resource development programs that have been implemented, so as to know the causes of these failures (Cetinkaya,Kirtepe \& Ugurlu 2018).

The failure of human resource quality development programs can be seen from the achievement of organizational goals that are inconsistent with the expectations or standards of work of the organization. It could be due to the failure to apply the principles of professional management and proper use of the model development. Failure will result in the following, namely: material loss, financial loss, organization's name loss, a decrease in employee benefits, decreased motivation/morale, the lower of organization competitiveness and the last impact is the drop in performance or profitability.

Armstrong (2006) research on human development analysis with performance of work indicators mentioned that the implementation of training by companies often fail to achieve optimal performance enhancement. Due to the lack of focus in conducting training needs analysis as well as conventional training patterns. Thus the inability to respond to the training needs of the organization, individual employees and the need for work. It is important in a company producing quality human resources in accordance to company strategy and needs that determine the type of development that have an impact on task demands (Satispi, 2018).

\section{Problem Identification}

Based on the description above can be formulated that researcher in conducting this study intent as follows:

1. Describing organizational culture and training activities in Bandung Polytechnic LP3I?

2. Was SDM training process that has been done has been effective and in accordance with the company organizational culture?

3. How the organizational culture-oriented training design in Bandung Polytechnic LP3I?

\section{Research Objectives and Benefits}

\subsection{Research Objectives}

The goal of this research is:

1. Conduct analysis of the organizational culture implementation and training needs planning.

2. Conduct training programs and training results analysis.

3. Conduct training plans analysis provide recommendations on a model on organizational culture oriented training.

\subsection{Research Benefits}

This study is expected to provide beneficial results, in line with the research objectives above. The author also hopes to conduct this research will obtain useful results that can be academically and practically.

This study is expected to provide practical benefits for Bandung Polytechnic LP3I on how to design a competency-based human resource training needs appropriate for all employees in order to implement the organizational culture, so that the performance and productivity of employees also increased and then eventually give optimum results for the company so can enhance the company's competitive advantage.

\section{Literature Review}

\subsection{Training}

At this time, the organization recognizes the importance to held human resources training and development because employee today is a very important asset in achieving organizational goals that have been set. Armstrong (2006) states the basic philosophy in human resource development the training and development is often done in an effort to improve the performance of the employee is deemed not able to carry out his job. In the stage of improving human resources performance, there are two important aspects that cannot be separated, i.e., training activity and human resource development activity that intended to use effectively the employee's potential. Training activities are seen 
as the beginnings by holding orientation process followed by an ongoing development program during these employees are in the organization.

Mathis \& Jackson (2006) stated that one of human resource functions in the process of human resource management is the training and development that means the training and development is very necessary to get appropriate employee as a good resource, training and development understanding is different. According to Gary Deshler (2004) training is intended to improve the mastery of various skills and techniques the implementation of certain work, detailed and regular. That training prepares employees (labor) to do those jobs. The development has a broader scope in an effort to improve and enhance the knowledge, abilities, attitudes and personality traits. In organizations, there is a dominant tendency to think training in terms of course program and this has been reinforced by the role played so far by the training function (Reed, Journals: 2006).

Effective training program is a valuable aid in career planning and development. There are two things that must be considered to achieve effective training. First, pay attention to the position of training in business processes. Secondly, related to the stages of training programming and implementing. In this phase, Gomes (2003) said there are at least three main stages in the training, namely: the determination of training needs, training program design, and training program evaluation (Horzum \& Izci 2018; Sijabat, 2018).

Determining the training need training needs analysis, is an ongoing process of collecting data to determine what training needs exist so that training can be developed to help organizations achieve goals. Conduct fundamental needs assessment to the success of the training program. Often, an organization will develop and implement training without first conducting a needs analysis. These organizations have a training risk that is, training too little or none at all (Brown, journals: 2002; Singh, 2018).

\subsection{Organizational Culture Oriented Training}

Organizational culture crystallized and continuously reformed dynamically over time. It is a set of shared assumptions (Schein, 1992; Sani Ibrahim, Mukhtar \& Gani 2017) about the world of work in a particular profession. These assumptions relate to concepts such as reality, truth, space and time that happen on individuals and groups (Wilkinson et. all, journals: 1996). Organizational culture is an important factor in the organization, this is due to the effectiveness of the organization can be determined by create a strong culture, which can be used to achieve organizational goals. A strong culture is a powerful tool to drive behavior, because it helps employees to do the job better, therefore every employee needs to understand the culture and how the culture been implemented.

In order to improve the knowledge, skills and attitudes conducive to job of employee's performance, then held employees education and training based on the needs analysis that combines the real conditions of a certain quality in line with the organization's long-term plan of the program. There are two strategies of education or training to do the organization according to Armstrong (2006), the education which is carried out within employee's workplace (on the job training) and education committed outside the employee's workplace (off-the-job training). Judith,et.al (2016) Strategy "on the job training" done by agencies to employees within work time while following education/training. These activities include job rotation where employees at any given time doing a series of jobs. Employees are internally trained and mentored by others employees who have highly skilled and the authority to train.

Off the job training methods do work outside the employee's workplace. Education or training refers to the actual work (simulationHadebe \& Khumalo 2018). The goal is to avoid the pressures that may influence the course of the learning process. This method can also be done in the classroom with seminars, lectures with educational film about the human resources, 'job rotation' relates to the temporary removal of a person/group of employees from one position to another, so that they can extend the experience of the various aspects of agency operations.

\subsection{OCAI (Organization Culture Assessment Instrument)}

Researches on organizational culture development in general use OCAI (Organization Culture Assessment Instrument) method developed by Kim Cameron and Robert Quinn.

OCAI serves to determine the proportions of the four types of culture on organizational culture that found concrete organizational culture. OCAI may also spoke about the strength or weight of four setting values in the organizational culture of an organization. The four options that correspond to the four types of organizational culture in the competing values framework formulated in any questions asked about certain aspects.

\subsubsection{Clan}

The working environment in a high clan organizational culture style is a culture style that shows friendly organization environment. People have a lot in common, and it is similar to a large family. The leaders or executives 
viewed as a mentor or even perhaps as father figures. The organization is held together by loyalty and tradition; there is a large involvement among its employees. Organization emphasizes long-term human resources development and the colleague by moral togetherness. Success is defined in order to meet the client's needs of and taking care of the people, so that the organization promotes teamwork, participation, and consensus (Sanchita, Swain \& Mishra 2017).

\subsubsection{Market}

It is a results-based organization that emphasizes work on the finishing and getting things done. People are competitive and focused on the goal. Leaders are driving hard, producer, and rivals at the same time. They are tough and have high expectations. Emphasis on organization continued winning together. Reputation and success are the most important. The long-term focus on rival activities and objectives are reached. Market penetration and share is the definition of success. Competitive pricing and market leadership are important. Organization Style based on competition.

\subsubsection{Adhocracy}

In adhocracy organizational culture, courage for experimentation and innovation is the basis for determining the course of organizations to achieve the targets that have been set. This Cultural organization necessitates the presence of leaders and employees who are willing to take risks in the organization development. Lower adhocracy organizational culture from the employee is not a good synergy with the family-based and structured work environment.

\subsubsection{Hierarchy}

Leader Proud of coordination and organizational efficiency based on the procedures to decide what to do. Regulations and maintain the organization's formal policy to maintain the smooth functioning of the organization is the most important. The long term goal is stability and results, coupled with the efficient execution and fluency tasks. Order delivery, smooth planning, and low cost define success.

\section{Methods}

In this study, researchers used a descriptive method that is trying to describe a phenomenon that emerged within the social/work operational, in other words, this study aims to describe the nature of things in progress at the time of the study. With a mixed data retrieval technique that is parallel both quantitative and qualitative. Where quantitative and qualitative data collected in the same time and analyzed to complement each other. In this study, a quantitative approach is used to map the company organizational culture, with calculate its tendency based on questioner and measure the company's needs. The qualitative approach is used to strengthen the data.

This research also through a case study approach which is detailed research on a certain object during a given period of time with sufficient depth and thorough. According Vrendenbregt (1987), a case study is an approach that aims to maintain the integrity (wholeness) of the object, meaning that the data collected in order to be a case study studied as a whole integrated, where the objective is to develop in-depth knowledge about the object.

According to Yin (2012) reason for doing research with a case study approach when the research question is regard to how or why, if researchers have little opportunity to control the events that will be investigated, and where his research focus is on contemporary phenomenon (the present ) in the context of real life.

In qualitative research, the research subject known as informants. The data source researchers select is the key informants and the informants who according to the author in accordance with the study. Key informants not only provide information about anything to researchers but also be able to advise on other sources of evidence that supports and creates access to the relevant sources (Yin: 2012; Sitorus, 2018). The selection of the study subjects by purposive, which is selected depending on the purpose of the research and the specific considerations, that is, those who are considered most knowledgeable about what is expected by the researchers.

\section{Results}

\subsection{Bandung Polytechnic LP3I Conditions}

Globalization era is rolling today, requires us to be more selective and deliberate in implementing education activities both short term and long term, so that what is expected to be achieved optimally. Bandung Polytechnic LP3I experienced 18 years of educating and training as well as deliver graduates achieve their goals become educated personnel, skilled and professional with a Diploma-3 (Associate Expert), has a mission to provide the widest information about higher education, so that young people graduate high school or SMK or MAN choosing a good place to advanced learning in college. 
As a pioneer of Links \& Match education in Indonesia, which is right on target-oriented education in the world of work, industry and business, also without leaving the academic rules, then education institutions Bandung Polytechnic LP3I continue to evaluate and maintain the quality of education as well as to adjust the curriculum to the developments. Education systems Advancement have a positive impact on the community recognition, so that by 2006, all existing studies program has received accreditation from the National Accreditation Board for Higher Education (BAN-PT), Directorate General of Higher Education, Ministry of National Education.

The existence of a good network with business and industry, make the educational institutions Bandung Polytechnic LP3I, a college that the student have done apprenticeship or work practices in the fifth semester and already worked. Work placement at the time of taking the semester final project at VI. So when graduation with a Diploma-3 they've worked and gained a good career and needed by the business or industry. In addition, alumni can continue their studies to the undergraduate level (S1) while working. With a variety of advantages, the competitiveness of graduates of Bandung Polytechnic LP3I in the eyes of society, national leaders, especially Corporate Partners remain high and awake.

\subsection{Bandung Polytechnic LP3I Training Conditions}

Based on the research results using interviews and focus group discussions conducted in Bandung Polytechnic LP3I, it is known that in Bandung Polytechnic LP3I are not applicable methods of Training Needs Analysis (TNA) to determine what kind of training will be held in. Execution and implementation of training activities in Bandung Polytechnic LP3I not have a clear Training Needs Analysis so that running training did not bring the results adequate to what is desired, it can be seen from the existence of complaints from employers that revealed the absence of significant changes in work behavior trainee support the implementation of the work in which they are assigned. The user (boss) is also still complaining about the lack of a significant improvement of the workers returning from training activities. These conditions also result in the user being less trusting and reduce their commitment to training and focus to pursue targets that have been set by the company.

Lack of support and commitment of the supervisors in each unit to monitor and provide ongoing feedback makes employee's development process become optimal and makes the training runs in Bandung Polytechnic LP3I just like a routine event, the employee did not have more commitment to run training results but all is done on the basis of orders from superiors.

Other constraints exist among others; the issue of delivery of content in the training process is the availability of infrastructure and the ability of teachers or facilitators in the training. The infrastructure site for training activities is not adequate and unstructured training time. In addition, the ability of the teacher or facilitator training is less developed competence continues to make delivery of material relative to less than optimal.

Of all the existing problems we can conclude that the main problem of the ineffectiveness of the training process at the Bandung Polytechnic LP3I is not a system design training focused with what is expected by all employees of both the level of directors until the ordinary employees, it is certainly the result of training results is not optimal, despite being a cost which is certainly not small.

\section{Discussion}

\subsection{LP3I Organizational Culture Current Mapping}

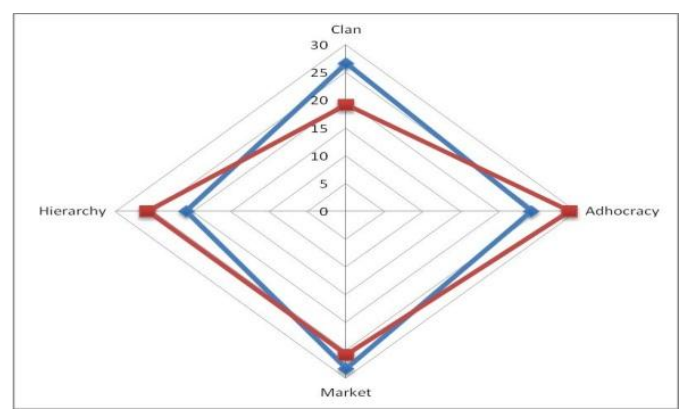

Based on the table it was found that Bandung Polytechnic LP3I organizational culture current profile of the order of the highest to the lowest influence is: clan, hierarchy, market and adhocracy. Behold the most dominant element is 
the culture clan with a percentage of $38 \%$ Polytechnic LP3I known as a strong familial element. Clan culture is used as an adhesive in Polytechnic LP3I organization. Members of the organization make the company as a container that unites every member with good interpersonal relationships, mutual trust and concern among members of the organization in the workplace.

\subsection{The Next Four Years Expected Organizational Culture Mapping}

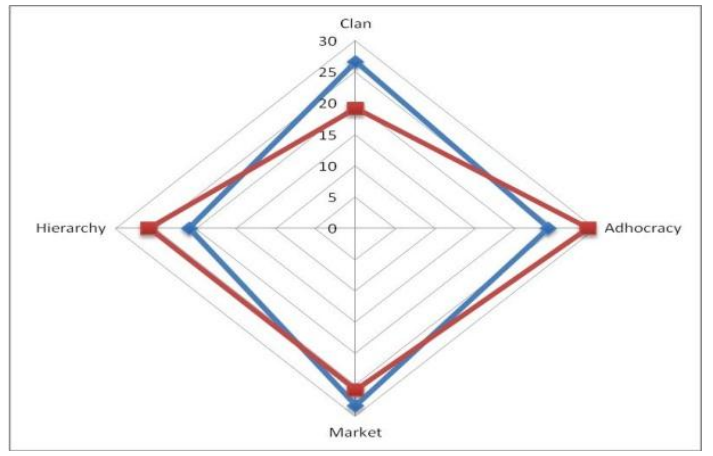

The data obtained results shows that the culture expected in four years is a Clan culture. Based on this we can see that there is no change between the current organizational cultural and also expected next four years, the employee retains Clan culture elements in the first place. This is because every employee is unable to release the strong relation that has become the hallmark of the company for many years, the employee feels comfortable with the figure of a mentor and facilitator as leader. Each person still wants an open culture, sharing, teamwork and a high level of awareness among employees. Member companies are also hoping to be given the opportunity to participate so as to create a reciprocal relationship between employees and managers. A leader who is able to demonstrate the consistency of the changes are also needed to be an example and role model, and will be used as a benchmark in acting in accordance with the expected culture.

\subsection{Training Policy Analysis}

Training needs analysis begins of training policy analysis, which is the official statement from the top leadership of the organization responsible for training field, both written statements and oral. Training policy is a statement in writing or orally, about decisions related to training priorities and approaches, methods and systems of training.

Training policy in Bandung Polytechnic LP3I until now also has held several organizational culture oriented trainings, namely through the implementation Mabit (night for faith and piety) are held regularly every Friday evening at the end of each month one time, in addition to the implementation yasinan (reading Quran) every Friday by all employees and managerial. All of this is done in order to improve the organization of cultural awareness organization.

\subsection{Gap Analysis}

OCAI profile mapping results at the employee level shows that the gap is relatively the same as the previous respondent. Employees are comfortable with the existing work environment, namely friendly working environment with hierarchies that keep running as it should. Achievement of targets and disclosure of creative ideas is lacking in the employee level respondents. Therefore, the gap of OCAI profile mapping at employee level between current organizational cultures and expected lie in the low market and adhocracy organizational culture.

In this study, the results of interviews and FGDs returned to participants or respondents to be studied together in an FGD for determination of gap that exist in Bandung LP3I. Having returned and reviewed by representatives of each respondent in the FGD gap determination, it was agreed that the gap of applied organizational culture and expected in Bandung LP3I is the low achievement and low targets innovations in the implementation and completion of tasks. Agreement that gap can be seen in the following table. 


\begin{tabular}{|c|c|c|c|c|}
\hline Informant & Director & Chief Executive & Executive & employee \\
\hline OCAI Gap & - market & - market & - market & - market \\
\hline & - adhocracy & - adhocracy & - adhocracy & - adhocracy \\
\hline
\end{tabular}

\subsection{Training Needs Analysis}

Training needs based on existing gap, defined as training in order to increase employment orientation that aimed for market and training in order to increase employees potential to be more active and able to contribute their innovations in the task. Therefore it is necessary to held organizational culture-oriented training. Market organizational culture training seen from the potential participants that are divided into achievement targets training that require all employees as participants and leadership training to be able to guide employees to focus more on achieving target with the trainees at the level of chief executive and executive.

Training needs to improve adhocracy organizational culture focused on improving the quality of employees is to dig back employee potential and employee motivation to be able to express creative ideas and innovations in the implementation and completion of tasks. Adhocracy culture Training, this training is intended for all employees as participants in the training.

\subsection{Training Draft Recommendation}

Market and adhocracy organizational culture training recommendations is made to change the existing organizational culture which is centered on the clan and hierarchy organizational culture become an organizational culture that centers on the market and adhocracy. The existing clan and hierarchy organizational culture is the foundation in the patterns of communication and interaction in Bandung LP3I in running market and adhocracy organizational culture.

Based on the gap, having returned to the respondents using FGD methods known that the deficiencies exist in each of the organizational culture considered low. In market organizational culture, respondents considered that the achievement of targets and completion of tasks perceived shortcomings in terms of:

\subsubsection{Leadership}

Work environment with a strong clan organizational culture make leader as a mentor or parent in the large family so that the leader does not perform its role as the driving force and engine of the company. At the level of the employee, the employee provides flexibility in the implementation and execution of tasks so that the completion of the task does not get close supervision of the leadership.

\subsubsection{Motivation}

Motivation in the task implementation and completion is still lacking by the leadership level. Similarly, at the level of the employee who sees the completion of the tasks and duties as the fulfillment of the work alone.

\subsubsection{Service}

Work environment that emphasizes familial give less attention to the consumer. The close relationship in the members of the company not tied out or on the relevant parties in achieving its targets. This raises a poor attitude in the fulfillment of customer needs so that is lacking in terms of services.

In adhocracy organizational culture gap, the results of a study of respondents in Bandung LP3I known that employees are lacking of make a positive contribution in the form of creative ideas and innovation in the development and implementation of task completion. Deficiencies in these gaps can be classified as follows:

\subsubsection{Creative Thinking}

Respondents tended to assume the tasks and task completion just a regular job so that respondents are more likely to carry out duties in accordance with existing operational standards. Respondents were reluctant to conduct experiments in the implementation and completion of tasks. 


\subsubsection{Emotional Control}

Lacking of understanding the emotional and spiritual quality in the work environment contribute to the lack of courage of respondents in expressing their creative ideas to your boss or fellow co-workers to achieve the implementation and completion of the task well.

\subsubsection{Training Model}

The training model that is specific to improving market and adhocracy organizational culture can be divided into the training model as follows:

\subsubsection{Market Organizational Culture Oriented Training}

\section{- $\quad$ AMT (Achievement Motivation Training)}

Achievement Motivation Training (AMT) is training packaged to motivate the participants to be the one to "perform." Motivation Training was first introduced by a professor of psychology at Harvard University, Prof. David McClelland. This training model has been tested against a variety of target participants and place and it worked encouraging participants to excel in their respective fields of work. Motivation was found to encourage the increase of competence so that the program model while creating high performance through a combination of increased motivation and competence.

Achievement Motivation Training (AMT) is a training program for self-development, especially in terms of improving participant's achievement motivation. So that was developed by the Achievement Motivation Training (AMT) is his achievement motivation. Objectives Achievement Motivation Training (AMT) is not to assess the personality of participants, but to help participants develop the achievement motive. Achievement motive developed by Achievement Motivation Training (AMT) is an impulse in a person who makes efforts to find satisfaction through achievement that is achieving.

In the world of work, Achievement Motivation Training (AMT) is designed to assist companies in an effort to improve the ability of its employees in terms of motivating themselves effectively. Employees who are able to motivate themselves effectively will greatly affect the daily work life and job satisfaction. With these capabilities, will be nurtured in employee morale to get achievement and keep trying to reap the best results.

\section{- $\quad$ Leadership Training}

Business environment development today's requires companies to strive hard in order to survive in the competition. HR as major capital determines the success or failure of a company. What is needed today is an independent human resources, have the attitude, commitment, and ability to constantly evolve. Therefore, many former leader providing instruction and control are no longer appropriate to the demands of the present. To establish the optimal performance required the HR leader who is able to develop the competence and commitment of subordinates by supporting, guiding and stimulating motivation of subordinates.

\section{- $\quad$ Excellent Public Service Training}

Service excellence is a must, any existing work and activities of the company, excellence serving absolutely owned. Apparently a lot of components in providing excellent service, and it can be learned. The concept of training, comprehensive materials and a team of trainers who are practitioners would make reliable participants in providing excellent service.

\subsubsection{Adhocracy Organizational Culture Oriented Training}

\section{- $\quad$ Creative Thinking Training}

The situation faced by companies today increasingly varied and complex. The variety and complexity of the situation requires different ways of solving problems. It makes logical-rational thinking skills alone becomes insufficient. Infrequently certain situations require creative problem solving. Therefore, the skills using techniques creative problem solving becomes important. By getting used to adjust the thinking patterns that correspond to particular situations, solving the problem will become more effective. This program invites participants to identify what and how to solve problems creatively.

Creative thinking is the process of moving new and useful ideas in some sphere, among others: the scope of the arts, business scope, the domestic sphere, the scope of science, etc. This expertise is a cognitive skill that involves stimulation of the brain to make new associations and connections in an effort to create an original thought - that's how creative ideas were made. 


\section{- $\quad$ ESQ (Emotional Spiritual Quotient)}

ESQ Training is a pioneer training honed with deep spiritual side, along with a person's emotional and intellectual side. ESQ is a recent innovation that aims to evoke the spiritual dimension of man. ESQ by carefully guiding principle in building a person's life and character based on emotional and spiritual. ESQ is also an attempt to bridge the world of business rationality with the spirit of divinity. Complete the success meaning with a deep spiritual value.

Participants Training Methodology will be guided to generate 7 basic values: honesty, responsibility, visionary, discipline, cooperation, fair, and caring. This value is already ingrained in humans since birth. Through this ESQ training, participants can be directed to achieve the basic values and help awaken the hidden powers and mobilize all his potential for life and work more productively.

\section{Conclusions and Recommendations}

\subsection{Conclusions}

Based on research analysis that has been described, it can be concluded that:

Training needs analysis results indicate that it is required organizational culture oriented training to improving the market and adhocracy organizational culture. The gap results shows that gap exist between applied organizational cultures with expected organizational culture is the market and adhocracy organizational culture. This gap was agreed by all respondents based on stratified random sampling with interviews and FGD method.

Training needs based on OCAI mapping and training needs analysis results shows that training needs of market organizational culture is focusing on achievement-oriented training and leadership training. The training needs of adhocracy organizational culture focused on creative thinking training and emotions control training.

Training model recommendations for market organizational culture-oriented is AMT (achievement motivation training), Leadership Training, and Excellent public service training.

Training model recommendations for adhocracy organizational culture oriented is creative thinking training and ESQ (Emotional Spiritual Quotient) training.

\subsection{Recommendations}

Author suggestions can give based on these results is as follows:

Market and adhocracy organizational culture variable is directly the most dominant factor that influence the achievement of targets in accordance with the vision and mission of the company. Therefore, leaders should pay closer attention to his employees. Provide support to constantly improve employees job performance can be done by providing an evaluation or work per three months, which each time discuss evaluation results employee are given direction and support to further enhance the market and adhocracy organizational culture oriented.

Adhocracy organizational culture should be further enhanced through the search for new ideas in performing the tasks that are employees themselves responsibility. In addition employees need to improve themselves or continuous learning. Recommended that leaders need to support and improve the behavior by adding library books that can be reviewed by the employee, even take the time to discuss in solving problems or simply broaden its employees knowledge.

\section{References}

Anderson, G. (1994). A proactive model for training needs analysis. Journal of European Industrial Training, 18. https://doi.org/10.1108/03090599410056577

Armstrong, M. (2006). A Handbook of Human Resource Management Practice (10th ed.). Kogan Page Limited London and Philadelphia

Brown, J. (2002). Training needs assessment: A must for developing an effective training program. Journal Public Personnel Management, 31. https://doi.org/10.1177/009102600203100412

Cetinkaya, T., Kirtepe, A., \& Ugurlu, F. M. (2018). Examination of the Attitudes of School of Physical Education and Sports Students towards Teaching Profession in Terms of Various Variables. Asian Journal of Education and Training, 4(2), 80-84. https://doi.org/10.20448/journal.522.2018.42.80.84

Crewell, J. W. (2008). Educational Research, Planning, Conducting, evaluating Qualitative and Quantitative Research. New Jersey: Pearson Merril: Prentice Hall.

Denison, D. R. (2001). Corporate Culture and Organizational Effectiveness. John Wiley \& Sons, Inc, Canada.

Dessler, G. (2004). Manajemen Sumber Daya Manusia. Buku 1, Edisi Sembilan, Alih Bahasa: Eli Tanya. PT. Indeks, Jakarta. 
Dubois. D. D., \& Rothwell. W. J. (2004). Competency - Based or Traditional Approach to Training. Retrieved from http://www.eric.ed.goy

Fred, L., (2006). Perilaku Organisasi. Andi, Yogyakarta.

Freeman, J. M. (1993). Human resources planning - Training needs analysis. Management Quarterly.

Gamba, F. J. (2017). Social capital in selected business associations of food processing SMEs in Tanzania and Rwanda: A synthetic-based approach. International Journal of Asian Social Science, 7(1), 63-84. https://doi.org/10.18488/journal.1/2017.7.1/1.1.63.84

George O Tasie. (2011, March). Competency-based training need analysis (TNA): An empirical study of Gulf University for Science and Technology. International Research Journal of Management and Business Studies, I(2). Retrieved from http: //www.interesjournal.org/IRJMBS

Hadebe, L. B., \& Khumalo, R. (2018). Assessing Key Performance Indicators in Government Secondary Schools of Matabeleland Region in Zimbabwe. International Journal of Education and Practice, 6(2), 84-106. https://doi.org/10.18488/journal.61.2018.62.84.106

Horzum, T., \& Izci, K. (2018). Preservice Turkish Teachers' Views and Perceived Competence Related to Inclusive Education. Journal of Education and e-Learning Research, 5(2), 131-143. https://doi.org/10.20448/journal.509.2018.52.131.143

Judith, O., Ijeoma, O., Ekere, K., Isaac, A., Christianah, I., Olubunmi, O., \& Martins, E. (2016). Popularity and Customer Preferences for Herbal Medicines in Nigeria: A Questionnaire Based Survey. Humanities and Social Sciences Letters, 4(3), 69-76. https://doi.org/10.18488/journal.73/2016.4.3/73.3.69.76

Karve, V. (2011). Introduction Training Organizational Values and Corporate Culture, Retrieved from http://karvediat.blogspot.com/2011/08/induction-training-organizational.html

Mathis, R. L., \& Jackson, J. H. (2001). Manajemen Sumber Daya Manusia.

McShane, V. G., et al. (2008). Organizational Behavior (4th ed.). McGraw Hill-International.

Rakab, M. B. (2018). The Frequency Effects of a Relatively Rarely Used Grammar Structure: The Case of Had Better. International Journal of English Language and Literature Studies, 7(4), 101-114.

Reed, J. (2006). What role can a training needs analysis play in organisational change. Journal of Organizational Change Management, 19. https://doi.org/10.1108/09534810610668382

Robbins, S. P. (2002). Teori Organisasi (3rd ed.). Alih Bahasa: Jusuf Udaya, Lic, Ec, PT. Arcan, Jakarta.

Robbins, S. P., \& Timothy, A. J. (2006). Organizatinal Behavior. Edisi ke-10, Pearson, Prentice Hall-New Jersey.

Sanchita, S., Swain, S. C., \& Mishra, B. (2017). A Framework to Study Organizational Trust and Support for Innovation with Reference to Performance of Dairy Sector in Ranchi (India). International Journal of Publication and Social Studies, 1(1), 10-15. https://doi.org/10.18488/journal.135/2016.1.1/135.1.10.15

Sandy, W. (2018). Factors Influencing Indonesian Students Satisfaction During their Studies in China. Asian Journal of Contemporary Education, 2(2), 136-148. https://doi.org/10.18488/journal.137.2018.22.136.148

Sani Ibrahim, S., Mukhtar, S., \& Gani, I. M. (2017). Relationship Between Electricity Consumption, Manufacturing Output and Financial Development: A New Evidence from Nigeria. Energy Economics Letters, 4(3), 28-35.

Satispi, E. (2018). Policy Development of the Child-Friendly City: Case Study of South Tangerang City Regional Government. International Journal of Social and Administrative Sciences, 3(2), 105-112.

Scein, E. (1997). Organizational Culture and Leadership. San Francisco.

Shi, K., An, Z., Nie, L., \& Meng, Y. (2018). Why Should the Authority Care about the Immigration Policy Uncertainty?. Asian Economic and Financial Review, 8(5), 641-652.

Sijabat, R. (2018). Understanding Behavioral Economics: A Narrative Perspective. Asian Development Policy Review, 6(2), 77-87. https://doi.org/10.18488/journal.107.2018.62.77.87

Singh, R. (2018). Perspectives on India-Bangladesh Water Dispute: The Farakka Barrage. Asian Themes in Social Sciences Research, 1(1), 14-20. https://doi.org/10.33094/journal.139.2018.11.14.20

Sitorus, R. R. (2018). Does E-Commerce Effect on Total Tax Paid through Taxpayer's Compliance?. Journal of Accounting, Business and Finance Research, 4(2), 40-48. https://doi.org/10.20448/2002.42.40.48

Wilkinson, M., et. al. (1996). Organizational culture change through training and cultural immersion. Journal of Organizational Change Management. https://doi.org/10.1108/09534819610124070 